$\xi=-1$

\title{
Spatial Model of Sky Brightness Magnitude in KUSZA Observatory, UniSZA
}

\author{
Roslan Umar ${ }^{1 *}$, Wardatul Jannah Awang², Siti Nadhirah Berzanji², Nur Farhana Abd Majed ${ }^{2}$, \\ Mohd Khairul Amri Kamarudin ${ }^{1}$, Musa Garba Abdullahi' ${ }^{1,3}$ \\ ${ }^{1}$ East Coast Environmental Research Institute (ESERI), Universiti Sultan Zainal Abidin, Gong Badak Campus, \\ 21300 Kuala Nerus, Terengganu, Malaysia \\ ${ }^{2}$ Islamic Astronomy Programme, Department of Fiqh and Usul, Academy of Islamic Studies, University of Malaya, \\ 50603 Kuala Lumpur, Malaysia \\ ${ }^{3}$ Department of Physics, Yusuf Maitama Sule University, Kano, P.M.B. 3220, Kofar Nasarawa, City Campus, Kano- Nigeria \\ *Corresponding author E-mail: roslan@unisza.edu.my
}

\begin{abstract}
Light pollution is the by-product of anthropogenic activities result from the increases in advanced economic and urbanization. Light pollution limits the ability to view the night sky by astronomers, on biodiversity, and ecosystems. This technology nowadays has led us to increase the convenient method to observe the brightness of night sky to determine how much the night sky polluted by artificial light. The study used SQM device and monitored the sky brightness of the KUSZA Observatory in Merang, Setiu, Terengganu, Malaysia. The results obtained were used to compare with the results obtained by simulation data generated from Earth Observation Group (EOG) of National Oceanic and Atmospheric Administration (NOAA), National Geophysical Data Center. It is the first world atlas of the artificial night sky brightness using GIS Interpolation tools. The result showed that the Kusza Observatory Merang is still appropriate to be the place of observation of celestial objects to either optical or radio astronomers. Hence, we recommended that through the data obtained from Defense Meteorological Satellite Program (DMSP) satellites, the value of sky brightness from all over the world can be used to make further analysis and to increase the precision of data recorded through observations. This study provides a clear view mapping of the accessing the sky condition using Geographic Information System (GIS) analysis in the study area.
\end{abstract}

Keywords: Light Pollution; Simulation; Sky Brightness; SQM; GIS

\section{Introduction}

The earth surface certainly changes through a day and night due to the electric light bulb invented in 1879 by Thomas Edison. Since then, the diurnal circle was tempered. This issue is related to light pollution which affects the ecological behavior and the optical astronomy which minimizes the ability to view the night sky [1]. Study of sky brightness is an essential topic in the field of astronomy, especially for optical astronomical observations that need clear and dark sky conditions [2]. The best sky condition required by astronomers is the clear sky hence light pollution became the most influential factor affecting the astronomers and astronomical observation [3].

This excessive amplification of light that affects the sky condition is called "Light Pollution." And in another word Light pollution is defined as any mortification of the capacity to view the sky during the night due to scattering of artificial lights in the atmosphere (P. Cinzano et al., 2001). Light Pollution has many sources such as the spectrum of an urban sky that usually shows a continuous glow, spanning the entire visible part of the electromagnetic spectrum [4]. According to Hassan et al., (2014) several primary factors are contributing to the night sky brightness such as the integrated light from distant galaxies, the integrated starlight within our galaxies, the zodiacal light, the night airglow, the Aurora, and twilight emission lines. Based on the types, those factors present in the atmosphere, are called the natural sources of light pollution. It can be scattered through the magnetic field, atom or molecules in the atmosphere within our galaxy.

However, the artificial light pollution result due to the rapid increases of urbanization, the amount of light on the earth surface nowadays cannot be controlled and continuously affect the night sky. These may include Light trespass, Sky glow, and glare and over-illumination. According to Riegel (1973), lighting would be growing hazard to optical astronomy [5]. International Dark-Sky Association (IDA) determine that almost 30 percent of light in the United States is amplified directly towards the skyward (Alex Kuczynski, 2003) which will affect the night sky conditions. National Space Agency (ANGKASA), Malaysia is considering the development of the Light Pollution Act to provide the regulation on the spillover of light caused by urban development. For example National Observatory in Langkawi, Malaysia must be protect from light pollution for the future [6].

For the sake of the mentioned researches above, most of their data used are provided by National Oceanic and Atmospheric Administration (NOAA), National Geophysical Center or Earth Observation Group (EOG). EOG started working in Defense Meteorological Satellite Program (DMSP) data since 1994. DMSP data are digitally recorded by DMSP satellite to measure the brightness of the earth at nighttime [3]. DMSP is based upon a series of earth-orbiting satellites whose primary function is the observation of weather, both day and night, by using sensors which make images in the visual and infrared bands [7].

However, during the simulation, the data are converted into candela units. Candelas are the units of luminous intensity and 


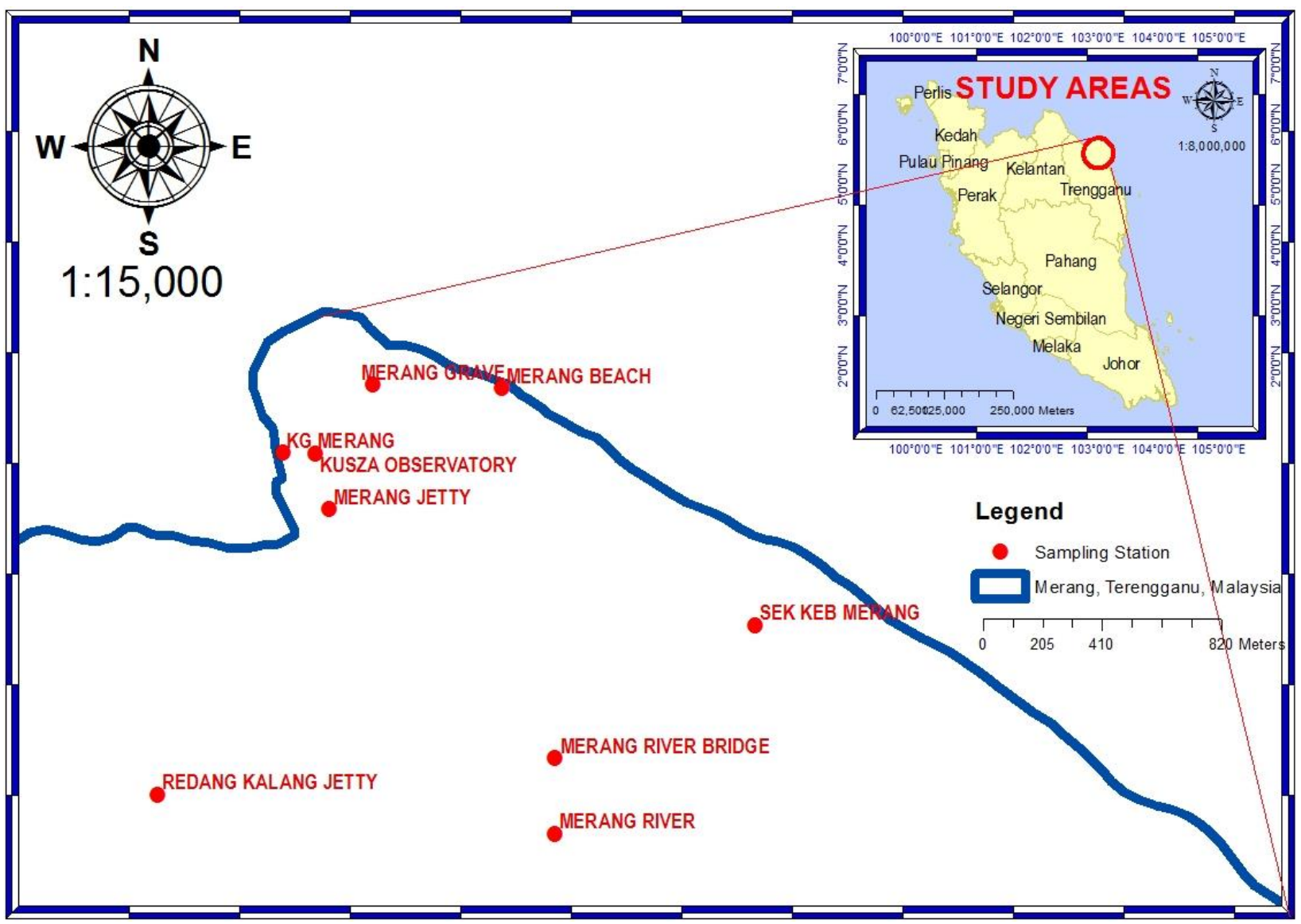

Fig. 1: Example of an image with an acceptable resolution

imagination of thin rays of lights. Every single beam has their luminous intensity values which measured in Candelas. The abbreviation for candela is cd [8].

Besides, the research used Sky Quality Meter (SQM) device and monitored the sky brightness of Merang station. The estimation and quantification of sky brightness have considerable advantages, primarily to preserve and conserve the KUSZA observatory from light pollution. This could be done by the help of technologies. Also, the value of SQM obtained from simulation was used and make comparisons of light pollution between simulation data and observation data.

Therefore, the primary objective of this research is to monitor the extent of light pollution that has occurred around the KUSZA observatory area by using GIS analysis and SQM. In this study, application of GIS tools will be used to run the spatial model of sky brightness in KUSZA Observatory, Merang, Setiu, Terengganu, Malaysia. This spatial model of sky brightness concentration is essential to show the darker and brighter sites for evaluating the level of light pollution in KUSZA Observatory.

\section{Methodology}

\subsection{Study Area}

The study was carried out in the area surrounded the KUSZA observatory station. It is located $102^{\circ} 57^{\prime} 50^{\prime \prime}$ East of Greenwich Meridian and $05^{\circ} 32^{\prime} 53^{\prime \prime}$ North of the Equator [9]. In this research, we collected the data in the location of 9 stations. We also used the data obtained from NOAA National Geophysical Centre [3] to fundamental technique to do the interpolation of several types of data. Different type of data may require different types of interpolation. This research used IDW as the principal method for the interpolation. IDW is among the modest means of validated the observed data has in this research of sky brightness studies.

There is nine (10) station including KUSZA Observatory for simulation and observation, as shown in Figure 1.

\subsection{Spatial Analysis Tool: Interpolation}

Geographical Information System (GIS) software, ArcGIS tool version 10.2 was used to distribute the data from this station spatially. Interpolation methods are used to create a surface grid in ArcGIS $[6,10]$. There are several interpolation methods such as Inverse Distance Weighting (IDW), Kriging, Spline, Natural Neighbor, Spline, Spline with Barriers, Topo to Raster, and Trend. Interpolation is a procedure to predict the values of cells at locations that lack sampled points. Spatial autocorrelation is the principle used to measure the relationship between the objects. In this study, there is primary subject to be focus these are correlations such as the similarity between the objects, the degree to which it's correlated and the level of interdependence as in Colin Childs, (2004).

This method would predict a point or area for all locations even if the measurements were not taking directly on the field. It will provide a clear view of some different values on a point within an area. A precise analysis can be achieved through this technique.

\subsection{Inverse Distance Weighting (IDW)}

IDW is one of the interpolation analysis provides by the ArcGIS software. IDW is under spatial analysis tool. This is the interpolation. It is based on estimate and assumption of a given value at the non-point location some distance from a given set of numbers. IDW are usually decreasing with the power of distance 
(inversely proportional to the weight and distance) [11] and mathematically represented in the equation below:

$$
f(r)=\sum_{i=1}^{m} w_{i} z\left(r_{i}\right)=\frac{\sum_{i=1}^{m} w_{i} z\left(r_{i}\right) /|r-r|^{p}}{\sum_{j=1}^{m} 1 /|r-r|^{p}}
$$

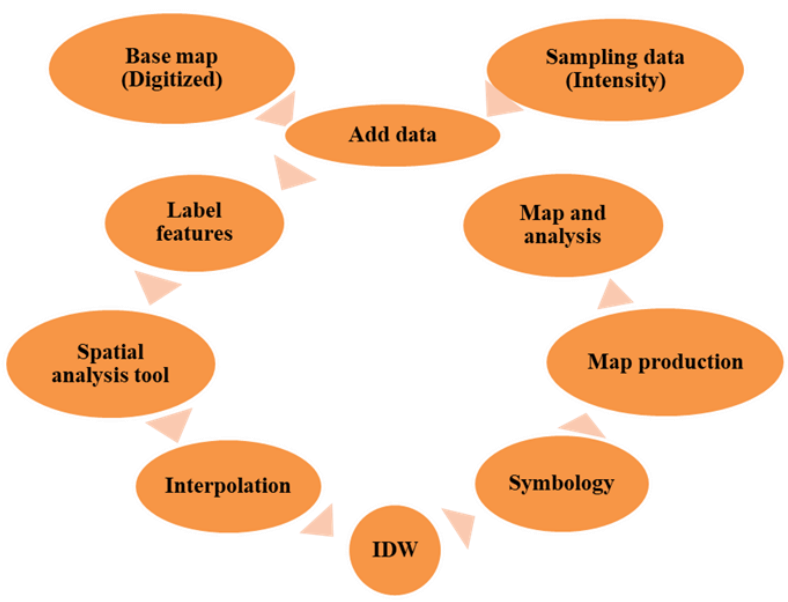

also help the ecologist and town planers to prevent and preserved the sites. Hence, it will alert the authority concerned in conserving the KUSZA observatory from light pollution, because it will be a hazard and distract the work dedicated to the station.

Table 1 further explained that high values of candela correspond to high light pollution of the area, while, places that has least pollution status or moderate shows low values of candela. Based on the Figure 3 (simulation) and Figure 4 (observation maps), the map shows the SQM reading value for simulation darker than the observation.

Refer to Table 1, SQM reading range for simulation between $\pm 2.273 \times 10^{-4} \mathrm{~cd} / \mathrm{m}^{2}\left(21.70 \mathrm{mag} / \mathrm{arcsec}^{2}\right)$ to $\pm 3.322 \times 10^{-4} \mathrm{~cd} / \mathrm{m}^{2}(21.28$ $\left.\mathrm{mag} / \operatorname{arcsec}^{2}\right)$. While for observation between $\pm 1.495 \times 10^{-4} \mathrm{~cd} / \mathrm{m}^{2}$ (19.65 mag/arcsec ${ }^{2}$ ) to $\pm 5.276 \times 10^{-4} \mathrm{~cd} / \mathrm{m}^{2}\left(20.78 \mathrm{mag} / \mathrm{arcsec}^{2}\right)$.

Fig.2: Flow Chart of Methodology for spatial analysis

Table 1: Result from simulation (NOAA) and observation

\begin{tabular}{|c|c|c|c|c|c|c|}
\hline \multirow{2}{*}{ Places } & \multirow{2}{*}{ Latitude (N) } & \multirow{2}{*}{ Longitude (E) } & \multicolumn{2}{|c|}{$\left(\mathrm{mag} / \operatorname{arcsec}^{2}\right)$} & \multicolumn{2}{|c|}{ Candela $\left(\mathrm{cd} / \mathrm{m}^{2}\right)$} \\
\hline & & & Simulation & Observation & Simulation & Observation \\
\hline Redang Kalang Jetty & 5.524947 & 102.942067 & 21.368 & 20.77775 & $3.064 \times 10^{-4}$ & $5.276 \times 10^{-4}$ \\
\hline Sek Keb Merang & 5.530188 & 102.960586 & 21.48 & 20.35 & $2.763 \times 10^{-4}$ & $7.824 \times 10^{-4}$ \\
\hline Kusza Observatory & 5.535511 & 102.946964 & 21.296 & 20.294 & $3.274 \times 10^{-4}$ & $8.238 \times 10^{-4}$ \\
\hline Merang River & 5.52372 & 102.954394 & 21.35 & 20.61475 & $3.115 \times 10^{-4}$ & $6.131 \times 10^{-4}$ \\
\hline Merang River Bridge & 5.526061 & 102.954394 & 21.47 & 20.668 & $2.789 \times 10^{-4}$ & $5.837 \times 10^{-4}$ \\
\hline Merang Grave & 5.537641 & 102.948736 & 21.692 & 20.08975 & $2.273 \times 10^{-4}$ & $9.943 \times 10^{-4}$ \\
\hline Merang Jetty & 5.533785 & 102.94739 & 21.28 & 19.64725 & $3.322 \times 10^{-3}$ & $1.495 \times 10^{-3}$ \\
\hline Kg Merang & 5.535528 & 102.945934 & 21.296 & 20.60475 & $3.274 \times 10^{-4}$ & $6.188 \times 10^{-4}$ \\
\hline Merang Beach & 5.537534 & 102.952733 & 21.332 & 20.738 & $3.167 \times 10^{-4}$ & $5.473 \times 10^{-4}$ \\
\hline
\end{tabular}

Where $r$, is the non-point location that leads to an estimator, $\mathrm{p}$, is a parameter (normally $\mathrm{p}=2$ ) as in the literature [12]. Consequently, this primary method is standard and easy to implement and is available in the GIS. Therefore, among the limitations of this approach are its practical applications [12, 13,14] and does not create the local shape implied by data and produces local extreme at the data points.

\section{Results and Discussions}

\subsection{Simulation and Observation}

Based on the data provided by NOAA National Geophysical Centre, there are nine stations in which the data was collected in Merang for the current year 2017. These data were arranged, validated, analysed, and interpolated into the map production according to GPS locations. Figure 3 showed the map of sky brightness in Merang constructed based on the data given. Using the information obtained by simulation and observation data, we compared both to see the extent of the impact of light pollution occurred around the KUSZA observatory area by using SQM and GIS analysis. This result was helpful as it will guide the researchers especially astronomers in knowing the class of the sky dealing with, so that to easily used the appropriate apparatus/instruments when conducting their observations. It will 


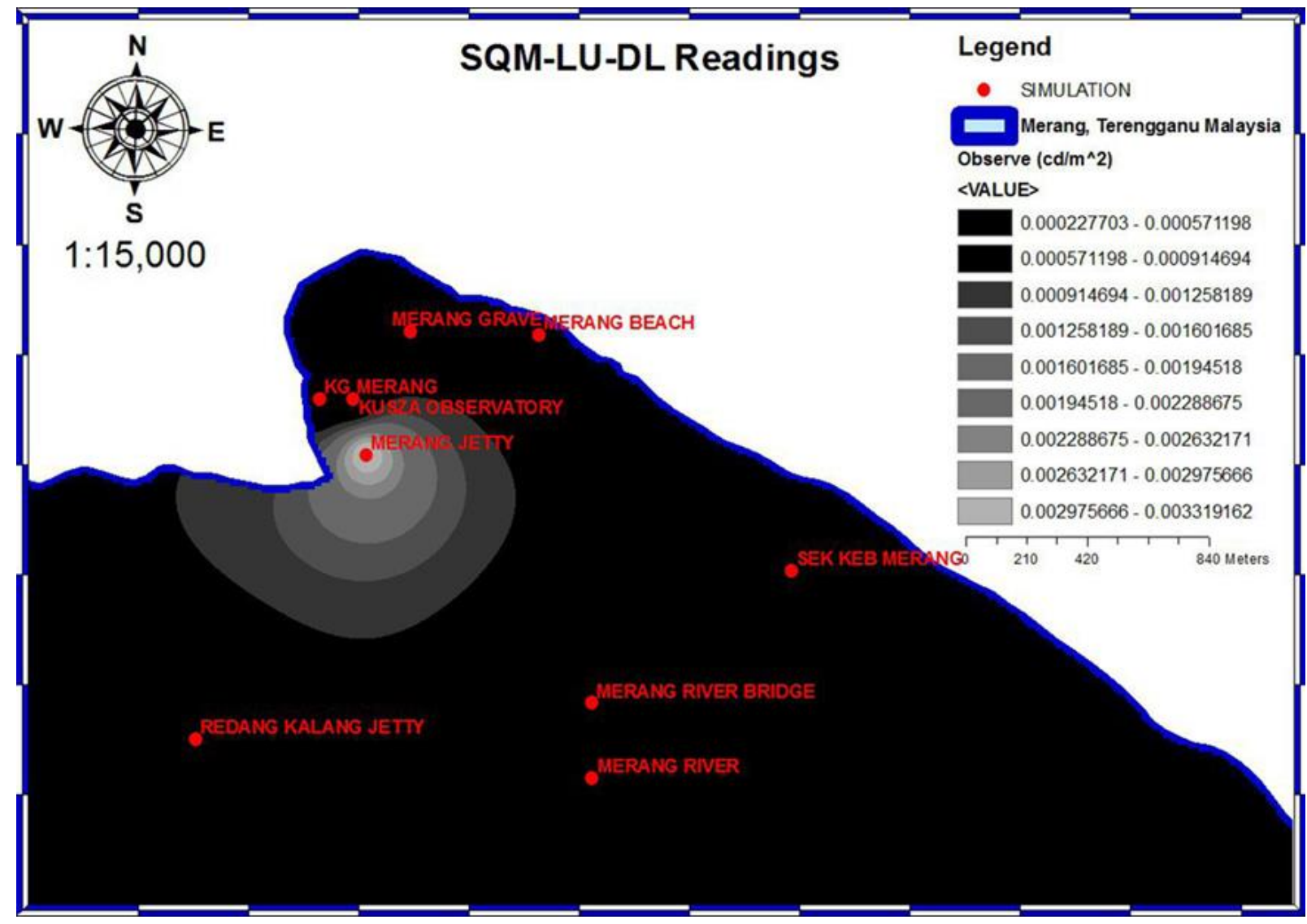

Fig.3: Spatial analysis for simulation

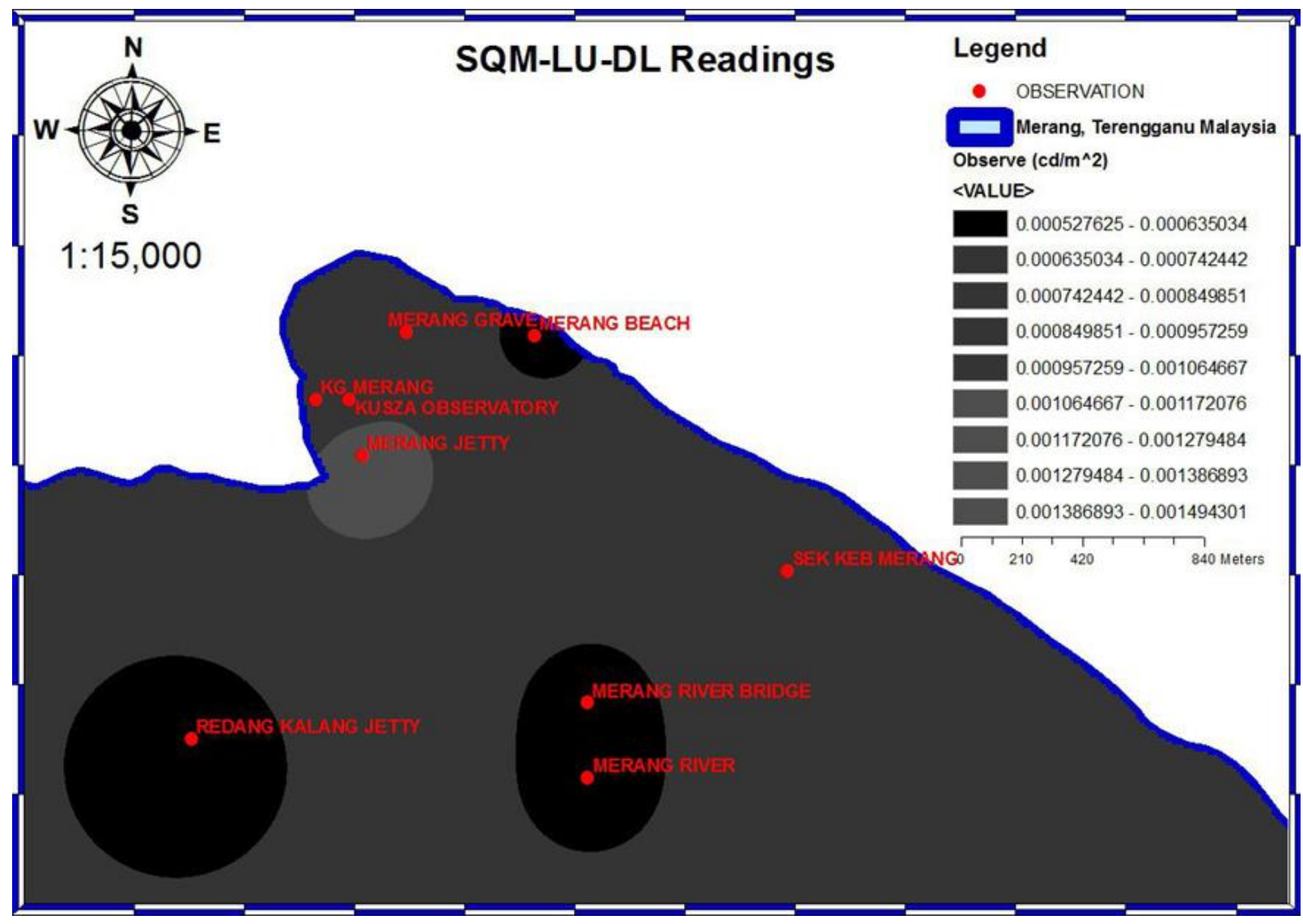

Fig.4: Spatial analysis for observation 


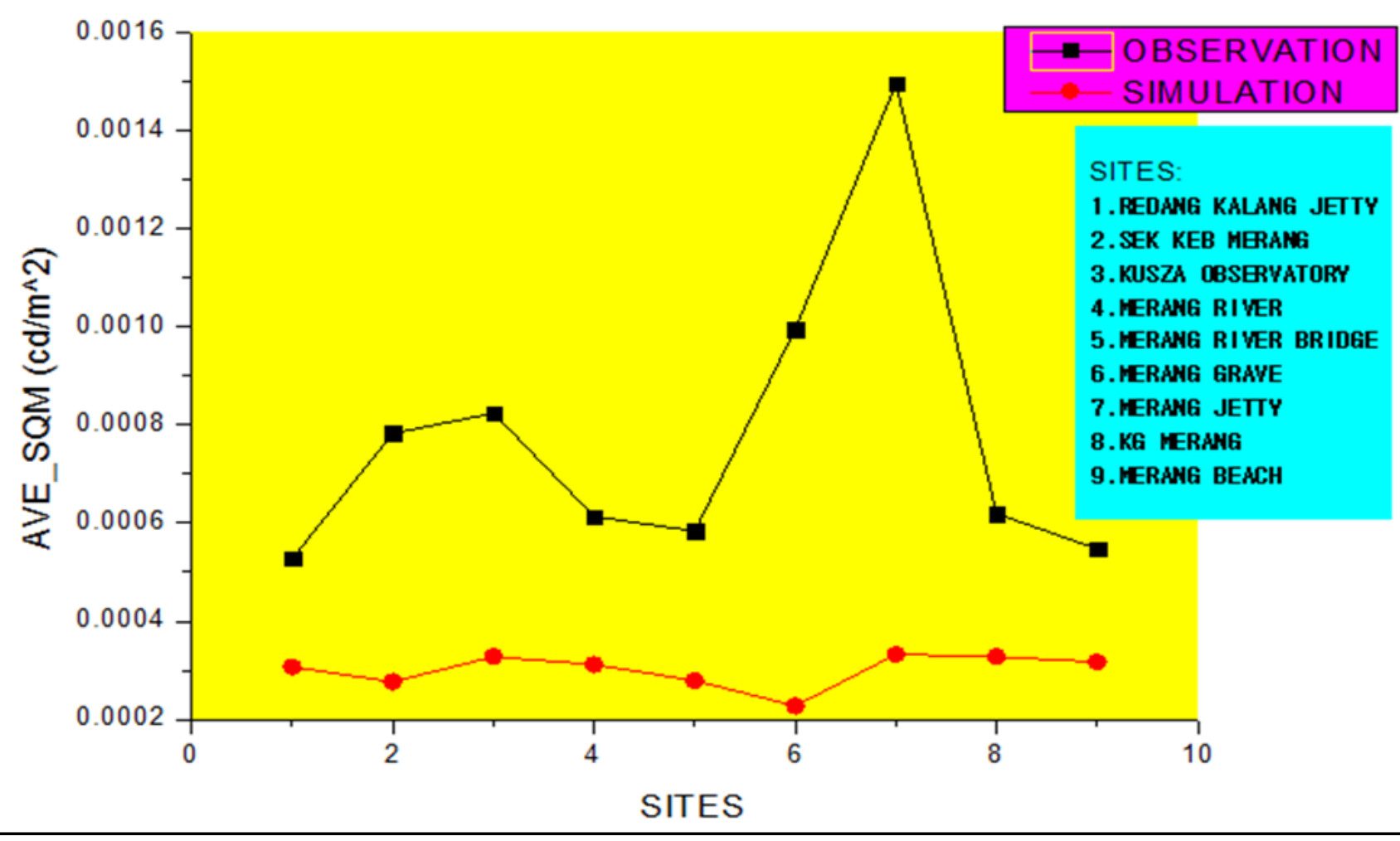

Fig. 5: Average magnitude of sky brightness between observation and simulation for all sites

\section{Conclusion}

In conclusion, we observed a significant difference between observation maps and simulation maps, but, both the SQM results in Tables 1; and the simulation results of the level of light pollution around the KUSZA observatory did not in the level that persist the activities carried out there. Subsequently, we still referred it as the class 3 (the middle class) and is still recoverable. Based on this study, the KUSZA observatory, Merang is still suitable to be the place of observation of celestial objects to either optical or radio astronomers. One of the locations of moon sighting that has been chosen by the King's Council is KUSZA Observatory. Hence, it's important to make sure this location is in good profile in terms of the brightness value of the sky. It is important to continue the legation of Islam in Malaysia [15].

For future research, we recommended the use of ArcGIS software due to its proficient. Hence, we recommended the users or the researchers first must be skilful in the use so that the selection of data station can be arranged with more strategic

We suggest that government should take action to prevent the location from exposure of light pollution such as to tighten the law about rampant installation of lamp, decoration sign post, and high lighting post for advert according to the criteria that allowed. This research will also recommend to the town planner and all the organisation concerned to make people awareness to understand the effect of artificial light at night to their environment, health, and distracting the behaviours of organism living around the area.

\section{Acknowledgement}

This study is made possible by the usage of the grant FRGS (FRGS/1/2015/SG02/UNISZA/02/1).

\section{References}

[1] Musa GA, Kamarudin,MKA, Roslan U, Azizah E, Saiful Iskandar K, Hafizan J. (2017) Night Sky Brightness Assessment in Nigeria
Using Environmetric and GIS Technique. International Journal on Advanced Science Engineering Information Technology Vol.7 (2017) No. 1 ISSN: 2088-5334 Pp. 28-34

[2] Allena AB, Rossing WAH, van der Werf W, Heusinkveld BG, Bukovinszky T \& Steingröver E (2012), Effect of light quality on movement of Pterostichus melanarius (Coleoptera: Carabidae). Journal of Applied Entomology 136, 793-800.

[3] Earth Observation Group, NOAA National Geophysical center, Dark Sky Company, LLC on the www.NASA.gov.com, www.NOAA.gov.com, http://www.lightpollutionmap.info ESRI, ARCgis spatial analyst, www.esri.com/spatialanalyst

[4] Bushnall D (2005), Observing the Deep Sky -an astronomer's companion. The Crowood Press Ltd Ramsbury, Marlborough Witlshire SN8 2HR 175, 68-69.

[5] Riegel KW (1973), Light Pollution 179, 4080.

[6] Tahar, M. R., Kamarudin, F., Umar, R., Kamarudin, M. K. A., Sabri, N. H., Ahmad, K., ... \& Baharim, M. S. A. (2017). Spatial Model of Sky Brightness Magnitude in Langkawi Island, Malaysia. Research in Astronomy and Astrophysics, 17(4), 037.

[7] Croft TA (1979), The Brightness of lights on earth at night, digitally recorded by DMSP satellite. U.S Geological Survey Reston, Virginia

[8] Ransen OF (2013), Candelas, Lumens and Lux, on the http://www.ransen.com/photometric

[9] Sabri, N. H., Umar, R., Shafie, M. M., Zafar, S. N. A. S., Mat, R, Ahmad, S., \& Ibrahim, Z. A. (2017). Correlation analysis of tropical rainforest climate effect on radio signal strength at KUSZA observatory, Terengganu. Advanced Science Letters, 23(2), 1268-1271.

[10] Abdullahi, M. G., Kamarudin, M. K. A., Umar, R., Endut, A. Khalit, S. I., \& Juahir, H. (2017). Night sky brightness assessment in Nigeria using environmetric and GIS technique. International Journal on Advanced Science, Engineering and Information Technology, 7(1), 28-34.

[11] Haque MN, Shahid S, Keramat M, \& Mohsenipour M (2016), GIS integration of hydrogeological and geoelectrical data for groundwater potential modeling in the western part of greater Kushtia district of Bangladesh. Water Resources 2, 283-291.

[12] Alvarado A, Esteller MV, Quentin E \& Exposito JL (2016), Multi-criteria decision analysis and GIS approach for prioritization of drinking water utilities protection based on their vulnerability to contamination. Water Resources Management 4 $1549-1566$ 
[13] Fathian F, Aliyari H, Kahya E \& Dehghan Z (2016), Temporal trends in precipitation using spatial techniques in GIS over Urmia Lake Basin. Iran. International Journal of Hydrology Science and Technology 1, 62-81.

[14] Abdullahi, M. G., Kamarudin, M. K. A., Umar, R., Endut, A.,

Khalit, S. I., \& Juahir, H. (2017). Night sky brightness assessment in Nigeria using environmetric and GIS technique. International Journal on Advanced Science, Engineering and Information Technology, 7(1), 28-34.

[15] Umar, R., Kamarudin, M. K. A., Wan, N. N., Yusra, A. I., Juahir H., Razali, M. R., \& Anuar, A. I. (2018). ASSESSMENT OF AHP FOR OPTICAL OBSERVATORY AND NEW MOON SIGHTING SITES IN PENINSULAR OF MALAYSIA. Journal of Fundamental and Applied Sciences, 10(1S), 432-444. 